\title{
A Descriptive Study: Assignment Area Preferences (Provinces) of Doctors and Dentists Who Participate in the Non-Permanent Personnel Appointment Program (PTT)
}

\section{Ingrid Masithoh}

Postgraduate Student Faculty of Public Health, Universitas Indonesia, Depok, Indonesia

\section{Abstract}

The lack of health workers in remote and rural areas is a worldwide concern. To solve this problem, the Indonesia Ministry of Health performed a program named Non-Permanent Personnel Appointment for doctors and dentists who serve in health centers throughout Indonesia, except for the islands of Java and Bali. It is aimed to fulfill the need for health workers in disadvantaged areas, borders, and islands as well as

Corresponding Author: Ingrid Masithoh ingrid.masithoh@gmail.com

Received: 26 December 2018 Accepted: 23 February 2019 Published: 7 March 2019

Publishing services provided by Knowledge E

(c) Ingrid Masithoh. This article is distributed under the terms of the Creative Commons

Attribution License, which permits unrestricted use and redistribution provided that the original author and source are credited.

Selection and Peer-review under the responsibility of the $2 \mathrm{nd}$ International Meeting of Public Health 2016 Conference Committee. in areas that were lacking doctors and dentists. This research was a descriptive study using secondary data from PTT applicants in the Bureau of Personnel in the Ministry of Health from 2010 to 2015, which aimed to identify the doctors' and dentists' choices of location (provinces) as areas of assignments. The result showed that at the national level, each year, the number of doctor applicants always exceeded the formation, while the structure of dentists still exceeded the number of applicants, except in 2013. West Sulawesi, Gorontalo, Central Sulawesi, North Sulawesi, Central Kalimantan, and Papua were provinces that were lacking doctor applicants, while Riau, Kepulauan Riau, South Sulawesi, West Sumatra, North Maluku, and Maluku were provinces with sufficient, even abundant number of dentist applicants. Conclusion: the number of doctors who applied for PTT was quite high, but the distribution was uneven (the island of Sumatera had the most senior applicants), while the number of dentists who applied for PTT was still less than the demand.

Keywords: Non-permanent personnel appointment (PTT); doctors PTT; dentists PTT; rural; remote.

\section{Introduction}

The world will be sort of 12.9 million health-care workers by 2035 (GHWA and WHO 2013). Even if a country has 'enough' doctors overall, they may not be distributed across geographical areas especially in rural and remote regions whereas innovative solutions are needed (Scott et al. 2013). Indonesia is no exception, in 2006, WHO reported that 
Indonesia was among 57 countries suffering a critical shortage of health workers (WHO 2006).

To solve this problem, Indonesia Ministry of Health performed a program named NonPermanent Personnel Appointment (PTT) for doctors and dentists who serve in health centers throughout Indonesia, except for the islands of Java and Bali. PTT doctor and dentist were not civil servants, appointed by the authority on health care facility for the short-term duration (Ministry of Health Republic Indonesia 2013). In 2015, the Ministry of Health had elected 1057 doctors and 459 dentists as PTT which conducted in April, June, September, and October 2015 (Personnel Bureau of Ministry of Health 2015). This study aimed to identify the doctors' and dentists' choices of location (provinces) as areas of assignments.

\section{Methods}

This research was a descriptive study using secondary data from PTT applicants in the Bureau of Personnel in the Ministry of Health from 2010 to 2015. The study populations was doctors and dentists who applied for PTT. Data consisted of PTT formation and applicant in every period in 26 provinces excluding Java island, Bali, and North Kalimantan. North Kalimantan excluded because data for North Kalimantan was only available since 2014 . This study compared the number of formation given by the Ministry of Health with the number of applicants. The comparison result was a ratio of applicants and structures in each province which trend could be viewed and compared.

\section{Results}

The result showed that at the national level, each year, the number of doctor applicants always exceeded the formations, while the structure of dentists still exceeded the number of applicants, except in 2013. Figure 1 and 2, they showed the national ratio of PTT applicants and formations for doctors and dentists from 2010 to 2015.

West Sulawesi, Gorontalo, Central Sulawesi, North Sulawesi, Central Kalimantan, and Papua were provinces that lack doctor applicants while Riau, Kepulauan Riau, South Sulawesi, West Sumatra, North Maluku, and Maluku were provinces with sufficient, even abundant number of dentist applicants. Figure 3 until Figure 14 showed the ratio of PTT applicants and formations in the region that stated above for doctors and dentists from 2010 to 2015.

Figure 3 to 8 showed six provinces that had suffered a lack of doctor applicants minimum two times. The other regions had never or only suffered the lack of doctor 


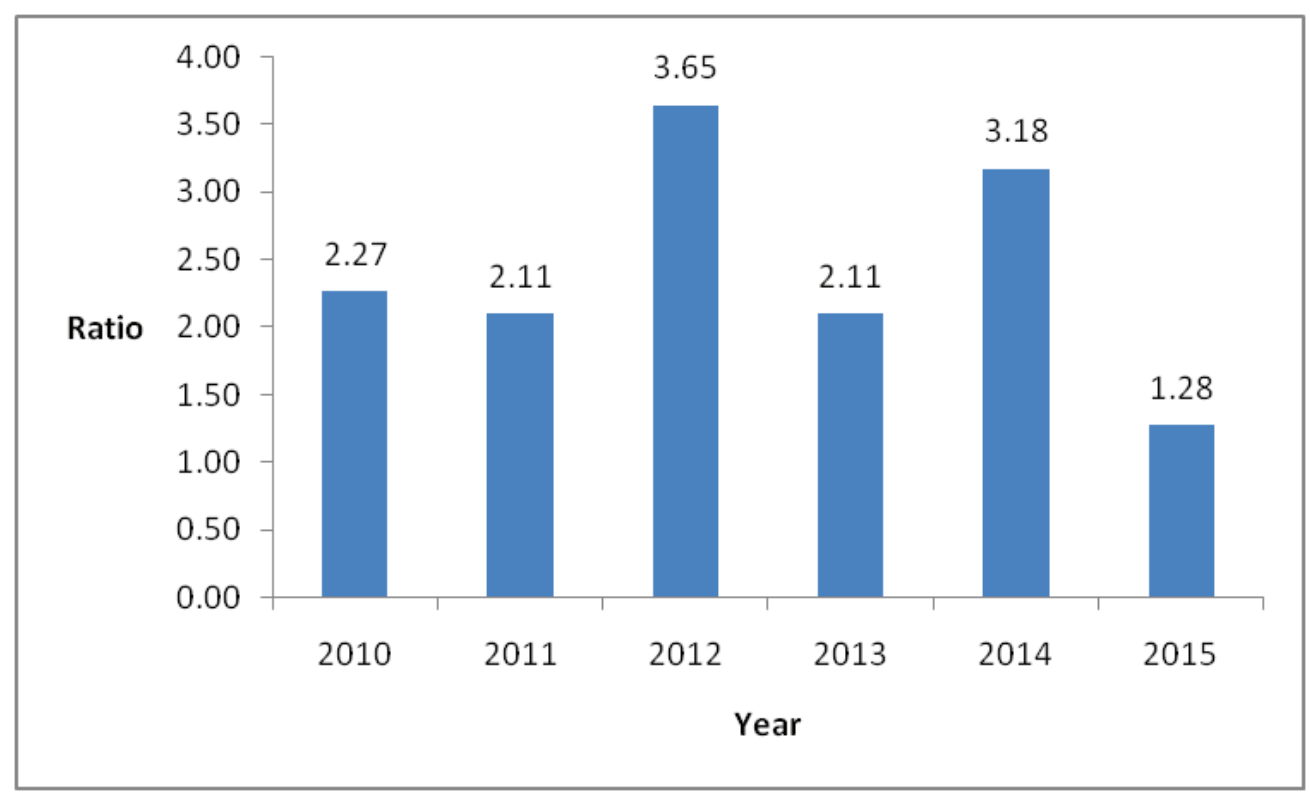

Figure 1: The ratio for Doctor's Applicant.

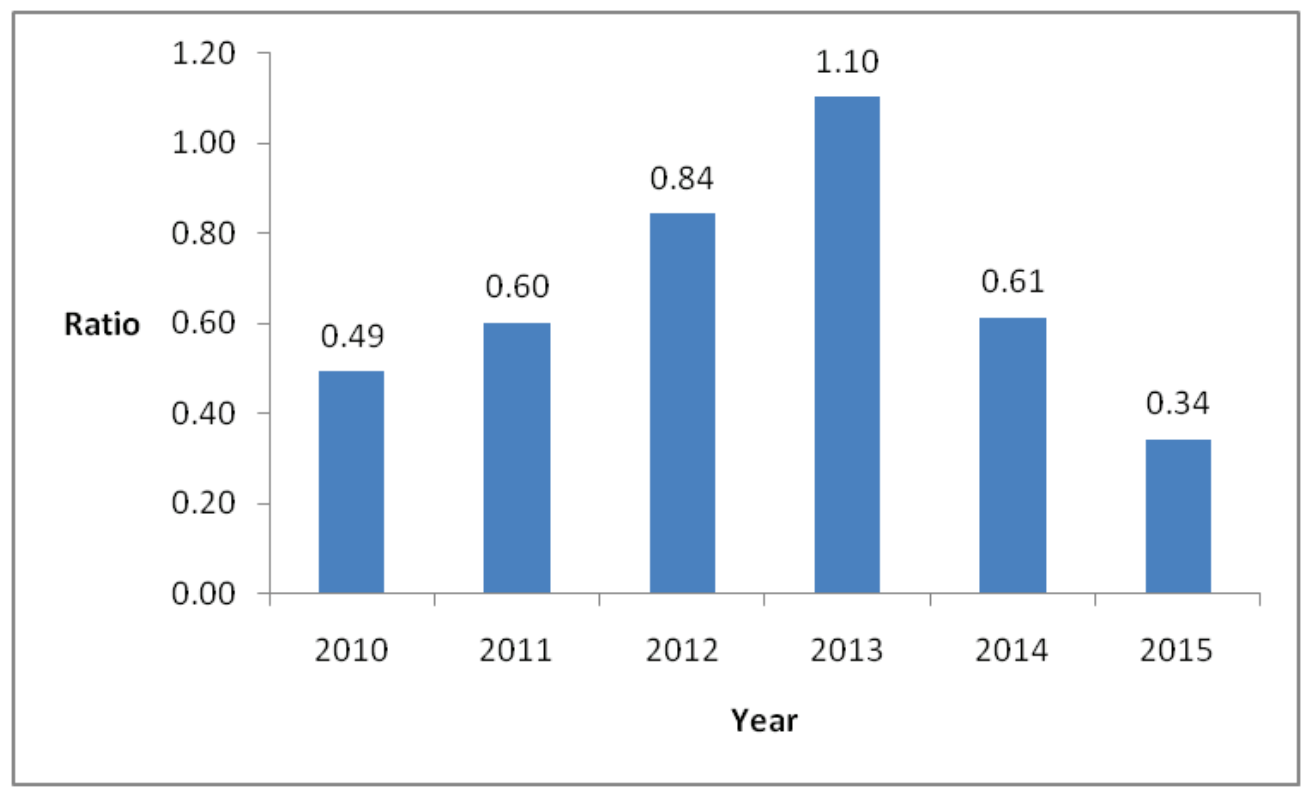

Figure 2: The ratio for Dentist's Applicant.

applicants once. The highest ratio ever achieved was in Riau in 2015, showing that there was only one doctor formation applied by 17.67 applicants. The lowest rate also happened in 2015 in West Sulawesi, which one doctor formation asked by 0.18 applicants.

Figure 9 to 14 showed six provinces that had more dentists' applicants than the other regions. The highest ratio ever achieved was in Riau in 2015, showing that there was 


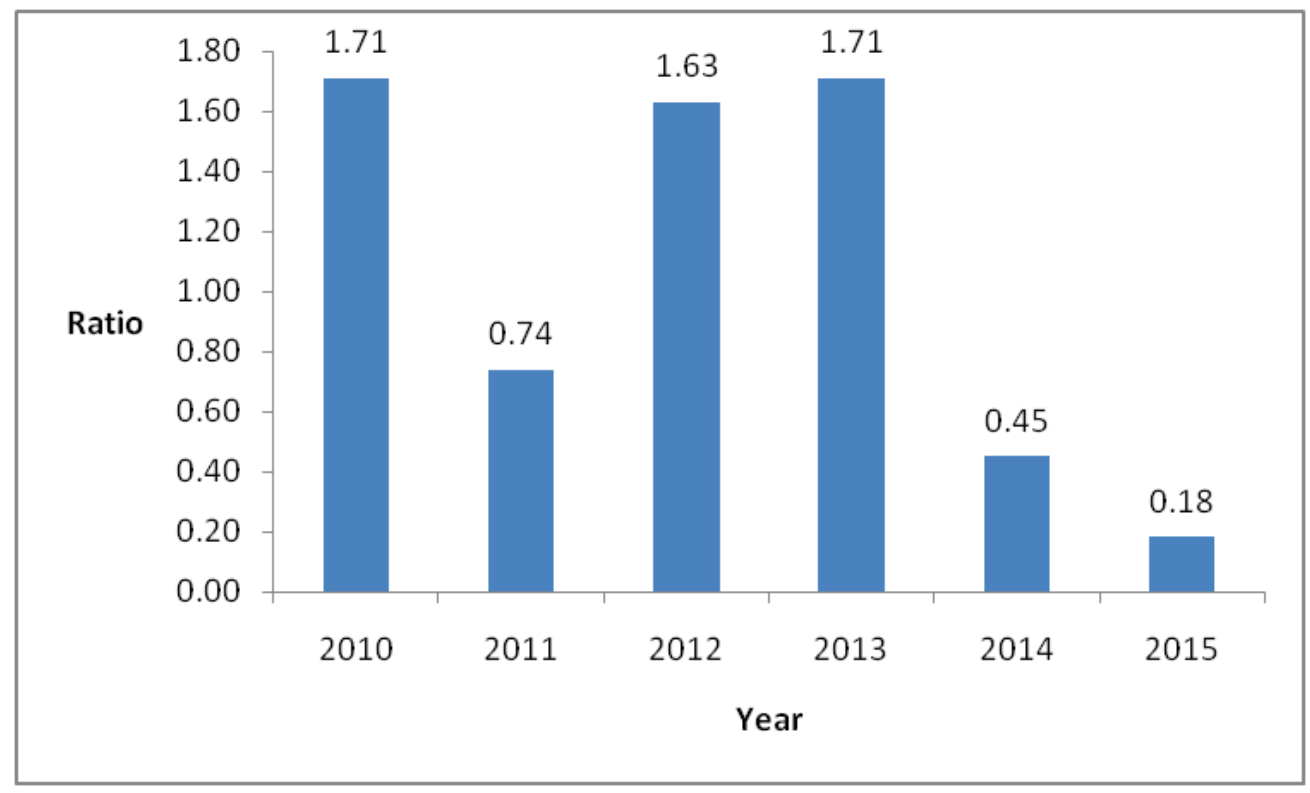

Figure 3: The ratio for Doctor Applicant in West Sulawesi.

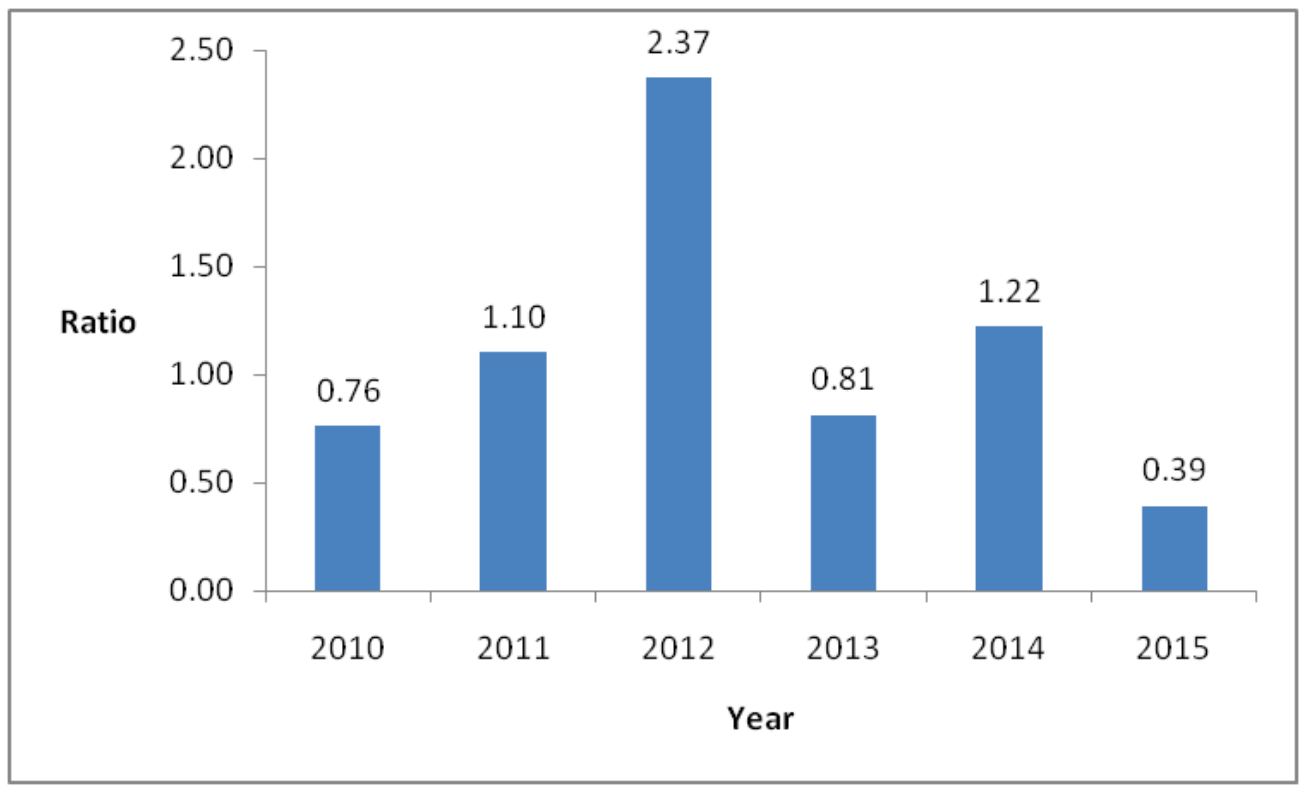

Figure 4: The ratio for Doctor Applicant in Gorontalo.

only one dentist formation applied by 5.14 applicants. The lowest rate happened in West Papua in 2014 which one dentist formation asked by 0.04 applicants.

\section{Discussion}

Personnel Bureau of Ministry of Health stated that there were 1,472 PTT doctors and 736 PTT dentists. Our finding and this data told us that doctors were more interested in 


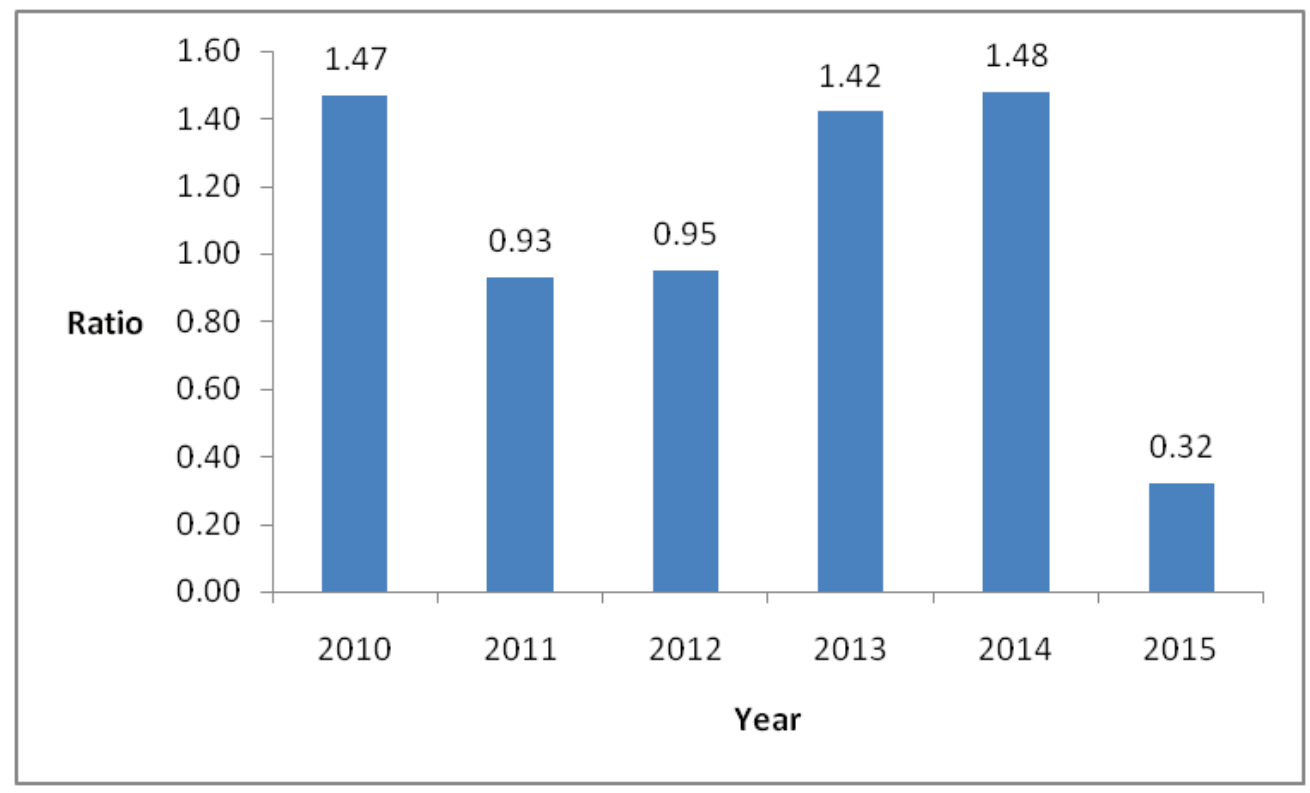

Figure 5: The ratio for Doctor Applicant in Central Sulawesi.

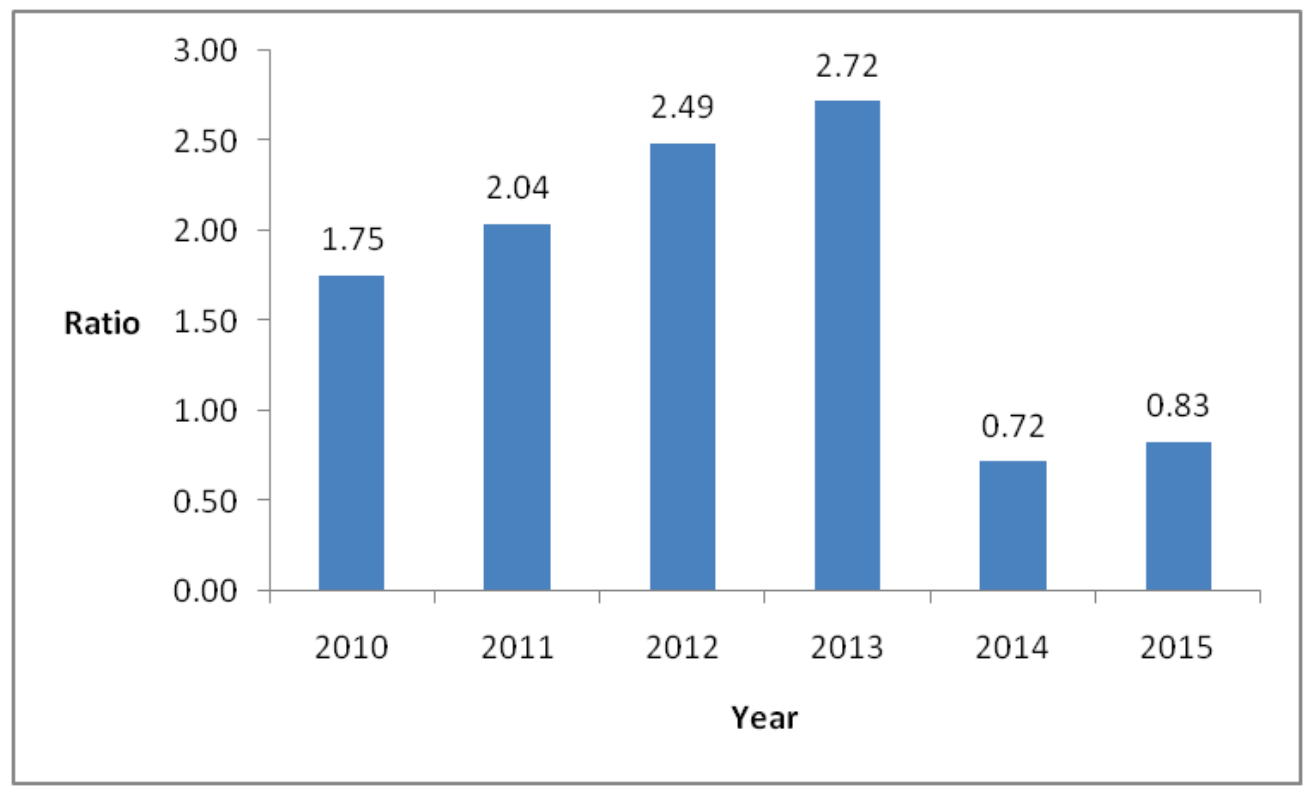

Figure 6: The ratio for Doctor Applicant in North Sulawesi.

joining PTT than the dentist, but there was still no study that showed us the reason why this happened.

The other finding was that West Sulawesi, Gorontalo, Central Sulawesi, North Sulawesi, Central Kalimantan, and Papua were provinces that lack doctor applicants while Riau, Kepulauan Riau, South Sulawesi, West Sumatra, North Maluku, and Maluku were provinces with sufficient, even abundant number of dentist applicants. Some 


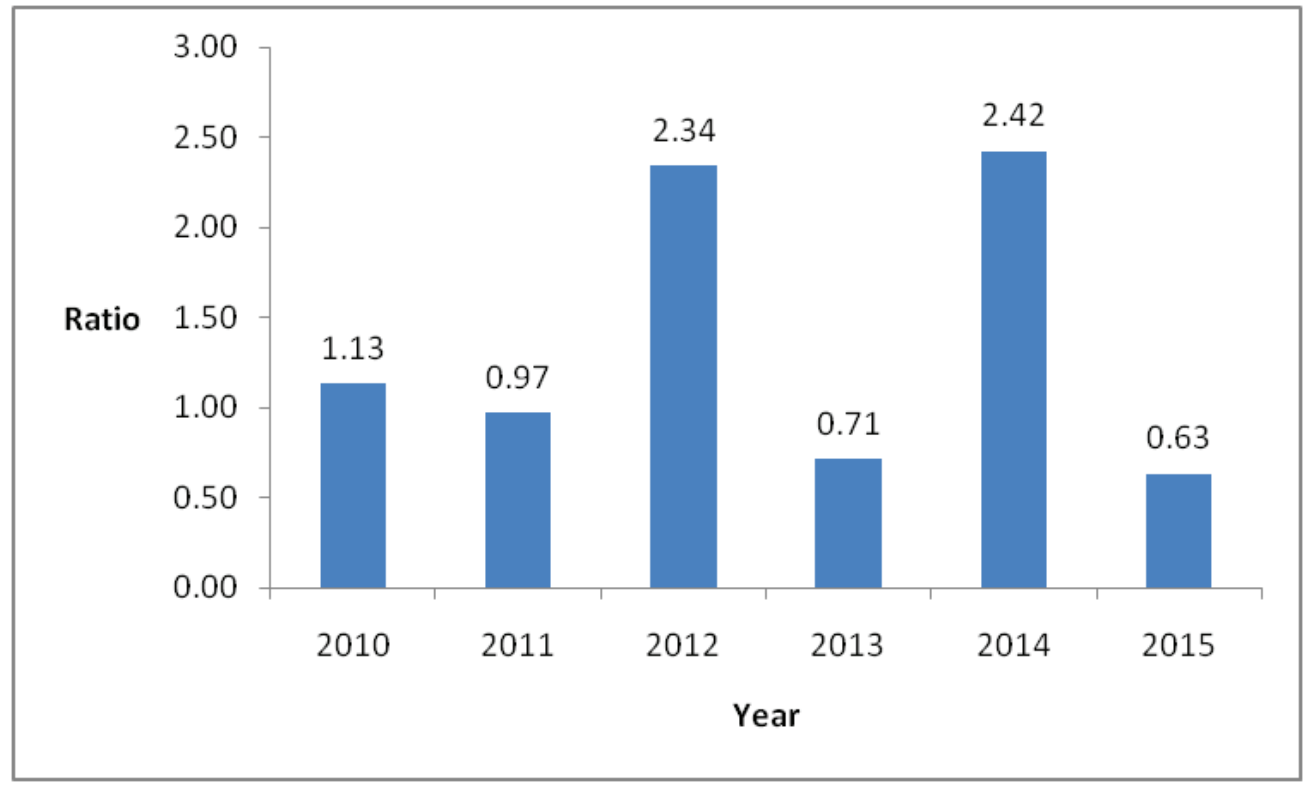

Figure 7: Ratio for Doctor Applicant in Central Kalimantan.

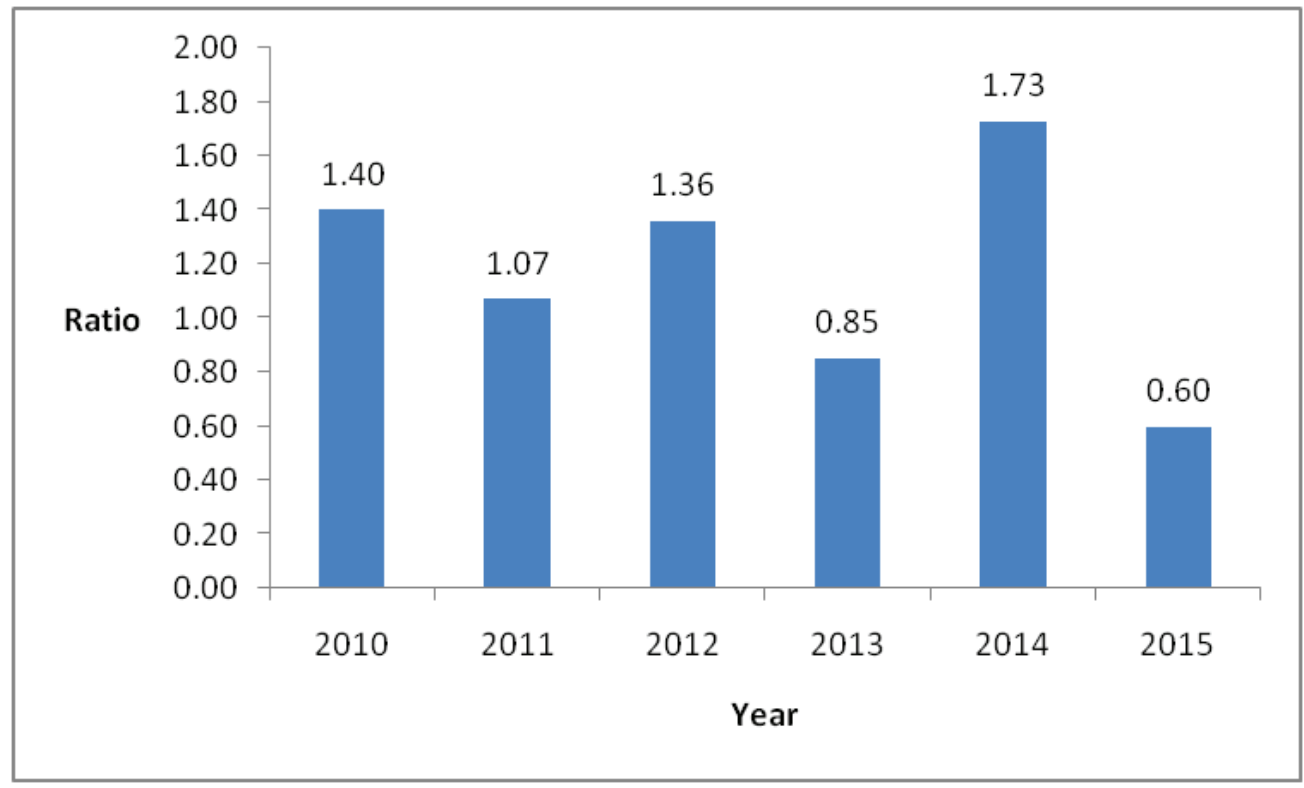

Figure 8: The ratio for Doctor Applicant in Papua.

studies stated that higher wages/salary increases acted as incentives to choose a rural area (Miranda et al. 2012; Hanson and Jack 2010; Holte et al. 2015) and this match with this study result. Based on the incentives data that was provided by the Personnel Bureau, the provinces that had more applicants gave additional financial incentives to doctor and dentist that work in their areas. Other than additional financial 


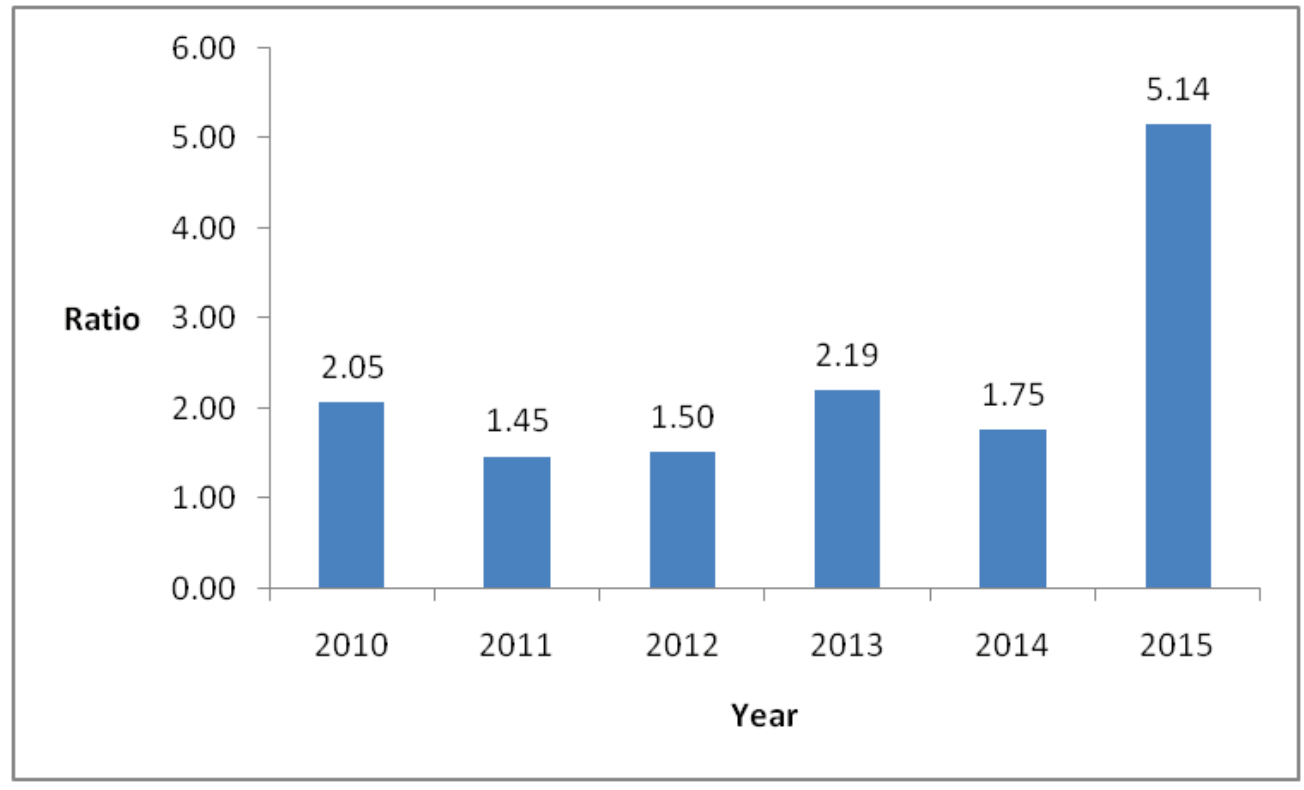

Figure 9: Ratio for Dentist Applicant in Riau.

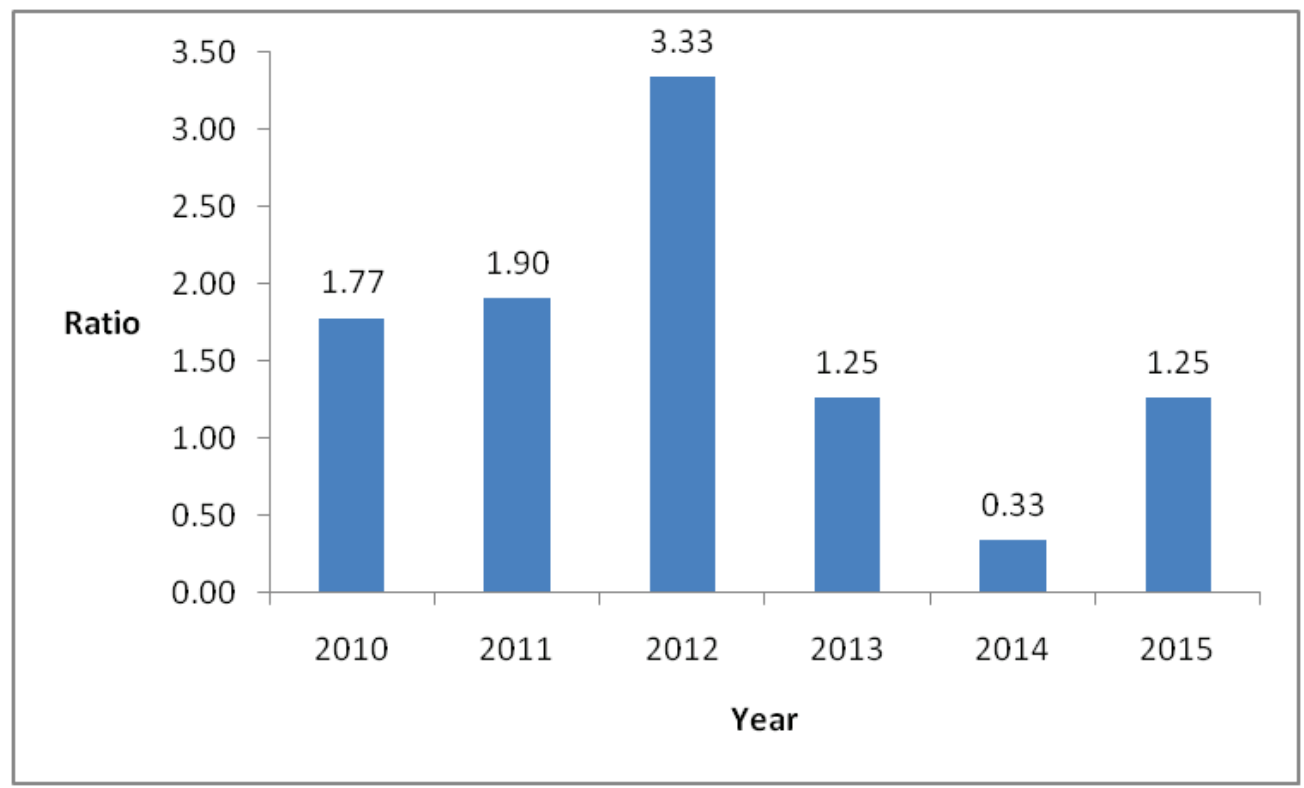

Figure 10: The ratio for Dentist Applicant in Kepulauan Riau.

incentives, safety also plays a role in choosing an assignment area (conflict areas had fewer applicants than the safe ones).

To solve this problem, the Ministry of Health should conduct a study to find out doctors' and dentists' preferences for choosing a job in rural or remote areas, so the Ministry of Health can issue appropriate policies. During this time, the government raised doctors' and dentists' financial incentives, but it still could not attract more dentists in joining PTT. 


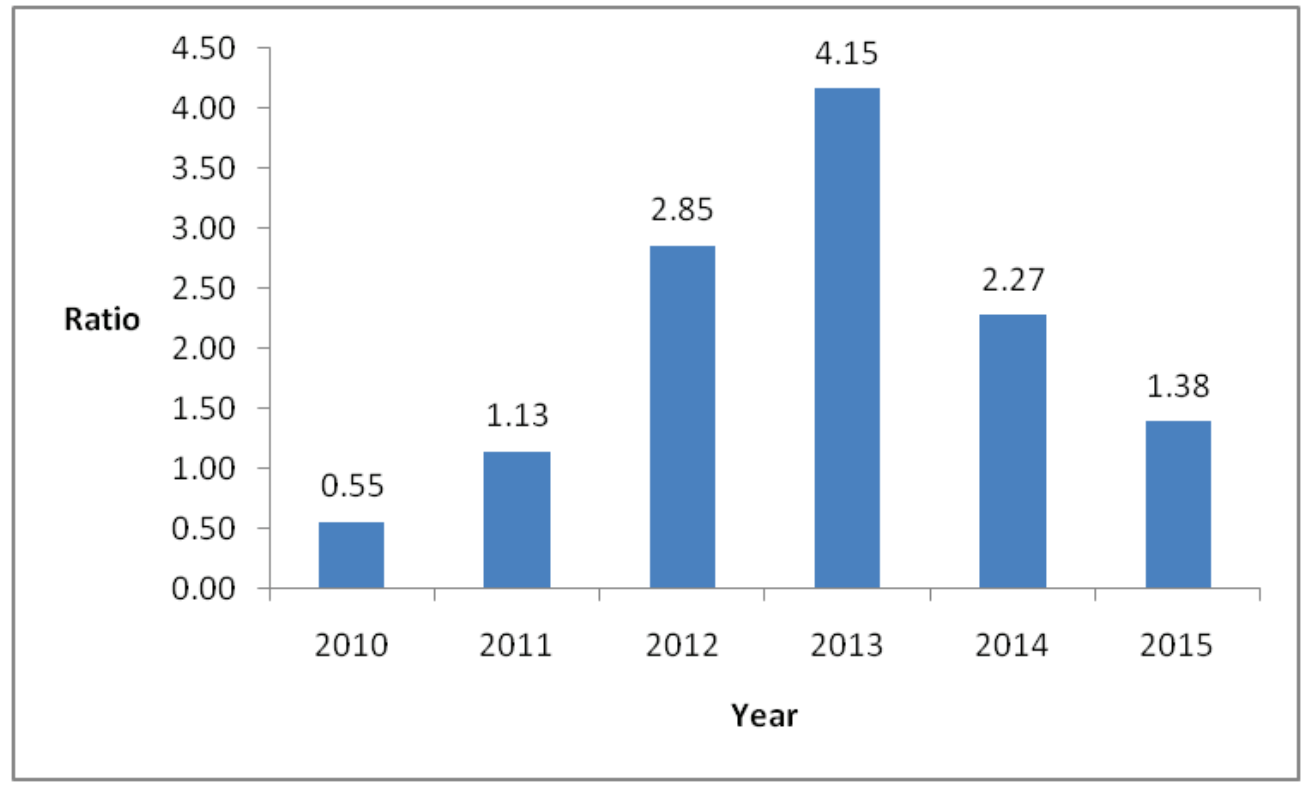

Figure 11: The ratio for Dentist Applicant in South Sulawesi.

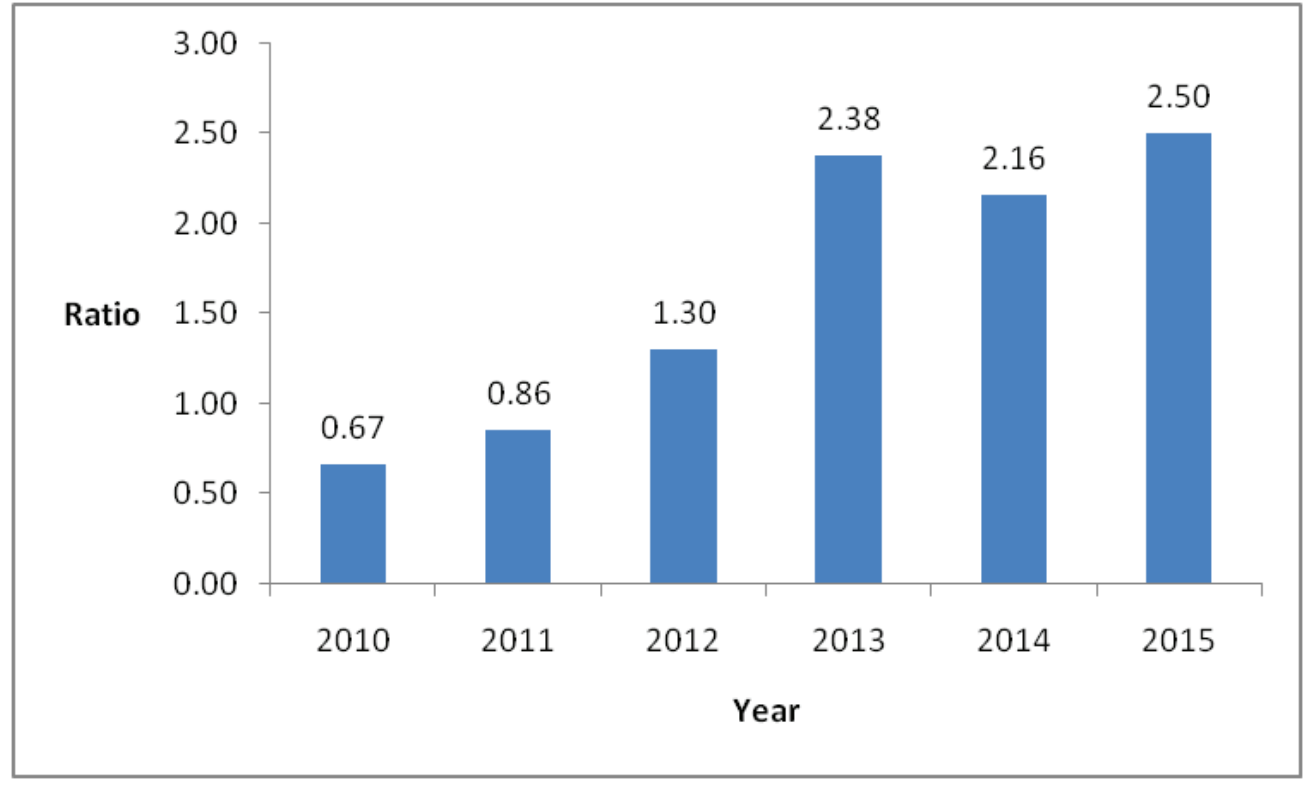

Figure 12: The ratio for Dentist Applicant in West Sumatra.

This study had some shortcoming. First, the result of this study only showed the ratio of PTT applicants and formations in province level, not regency level. So, it could not confirm the uneven distribution within a province, second, this study used secondary data that did not have the data about doctors' and dentists' reason for choosing their assignment area, so this study can only tell us about doctors' and dentists' assignment area preferences without knowing their exact reason. 


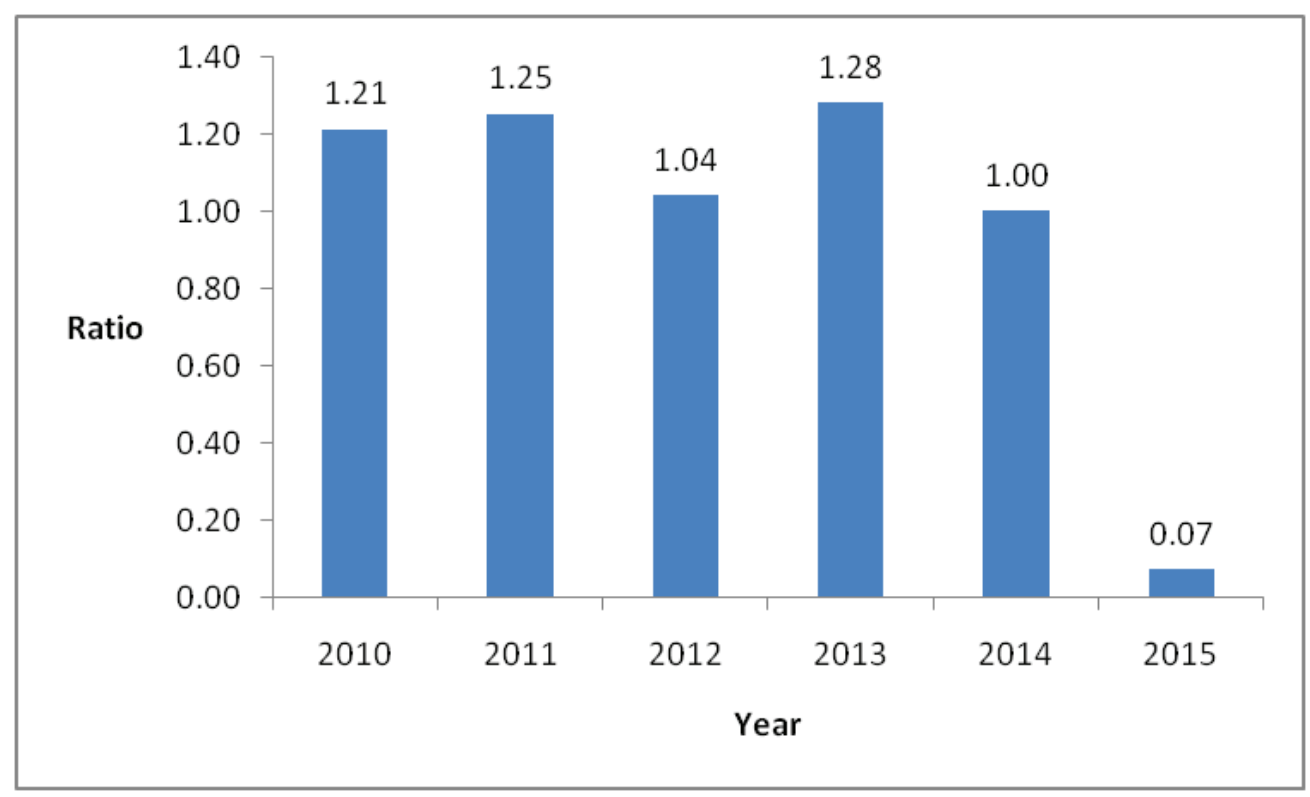

Figure 13: The ratio for Dentist Applicant in North Maluku.

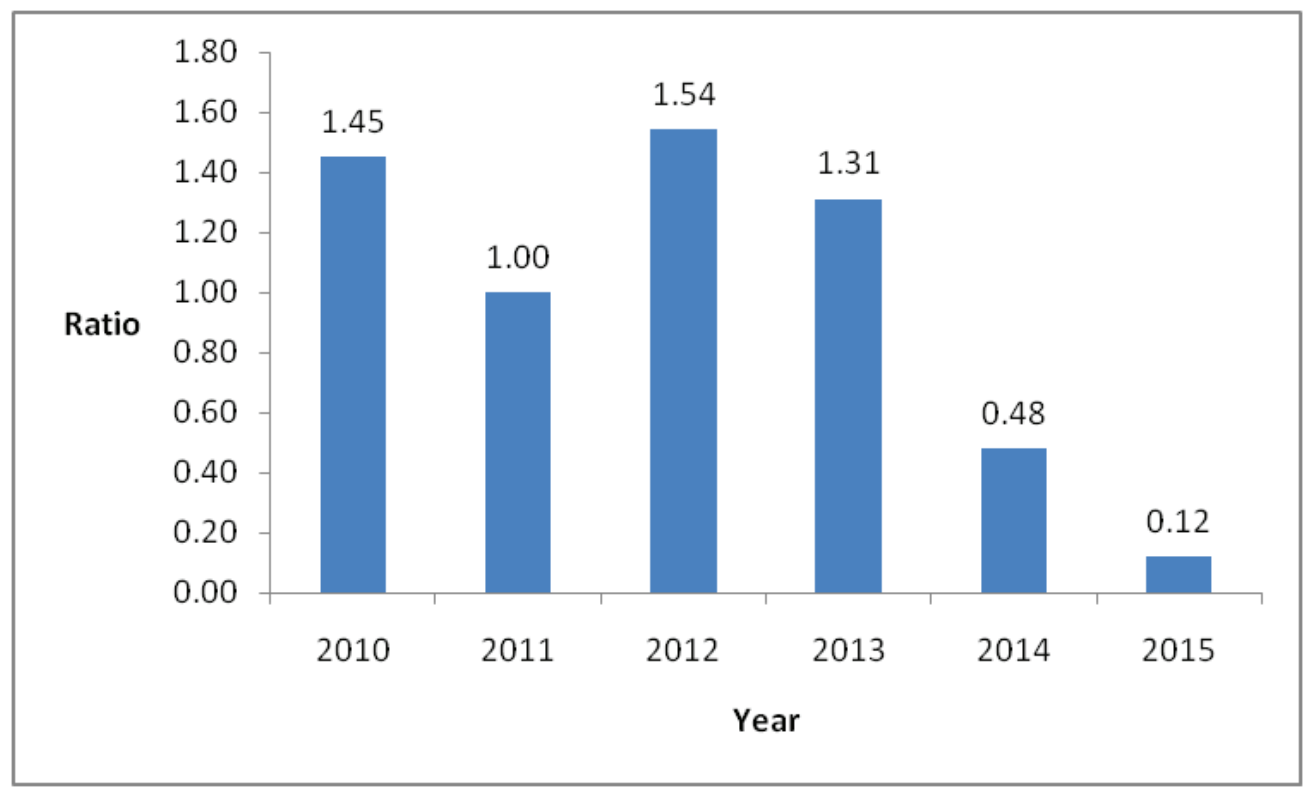

Figure 14: The ratio for Dentist Applicant in Maluku.

\section{Conclusion}

The number of doctors who applied for PTT was quite high, but the distribution was uneven (the island of Sumatera had the most senior applicants). The number of dentists who asked for PTT was still less than the demand. Government or researcher should 
conduct a study to find out doctors' and dentists' preferences for choosing a job in rural/remote/island areas of Indonesia.

\section{Acknowledgment}

Author thank the Bureau of Personnel of the Ministry of Health for the data and my colleagues who spent their time to proofread this work.

\section{References}

[1] GHWA, and WHO. 2013. "A Universal Truth: No Health Without a Workforce Third Global Forum on Human Resources for Health Report." WHO.

[2] Hanson, Kara, and William Jack. 2010. "Incentives Could Induce Ethiopian Doctors and Nurses to Work in Rural Settings." Health Affairs (Project Hope) 29 (8): 1452-60. doi:10.1377/hlthaff.2009.0164.

[3] Holte, Jon Helgheim, Trine Kjaer, Birgit Abelsen, and Jan Abel Olsen. 2015. "The Impact of Pecuniary and Non-Pecuniary Incentives for Attracting Young Doctors to Rural General Practice." Social Science \& Medicine 128 (March): 1-9. doi:10.1016/j.socscimed.2014.12.022.

[4] Ministry of Health Republic Indonesia. 2013. "Decree of the Minister of Health of the Republic of Indonesia Number 7 of 2013 on Guidelines for Doctors and Midwives' Appointment and Placement For Non-Permanent Personnel Appointment Program." Ministry of Health Republic Indonesia.

[5] Miranda, J. Jaime, Francisco Diez-Canseco, Claudia Lema, Andrés G. Lescano, Mylene Lagarde, Duane Blaauw, and Luis Huicho. 2012. "Stated Preferences of Doctors for Choosing a Job in Rural Areas of Peru: A Discrete Choice Experiment." Edited by Alfredo Luis Fort. PLoS ONE 7 (12): e50567. doi:10.1371/journal.pone.0050567.

[6] Personnel Bureau of Ministry of Health. 2015. "Activity Report囚: Physician and Midwife as Non-Permanent Personnel Appointment of 2015." Ministry of Health Republic Indonesia.

[7] Scott, Anthony, Julia Witt, John Humphreys, Catherine Joyce, Guyonne Kalb, SungHee Jeon, and Matthew McGrail. 2013. "Getting Doctors Into The Bush囚: General Practitioners' Preferences For Rural Location.” Social Science \& Medicine 96 (July): 33-44.

[8] WHO. 2006. "The World Health Report 2006 - Working Together for Health." WHO. 